CASE STUDY

\title{
Genuine Students as Partners: How a Teaching Assistant Consultant Program put Students as Partners into Practice
}

\author{
*Gerry Gourlay, Biology, University of Victoria, Victoria, British Columbia, Canada \\ Cynthia Korpan, Division of Learning and Teaching Support and Innovation, University of \\ Victoria, Victoria, British Columbia, Canada \\ Contact: holmgera@uvic.ca
}

\begin{abstract}
In this case study, a graduate student and staff member show how an institution wide program, aimed at enhancing learning and teaching in higher education, exemplifies Matthews's (2017) "Five Propositions for Genuine Students as Partners Practice" at the department level. To do so, we describe the five propositions in relation to the Teaching Assistant Consultant (TAC) program that positions a graduate student leader in each department to support new Teaching Assistants (TAs). Through comparison, we look at how the program is inclusive, exhibits strong power-sharing capabilities through continual reflection and conversation, is ethical, and is strongly transformative.
\end{abstract}

\section{KEYWORDS}

inclusive, transformative, Teaching Assistant Consultant, partnership, biology

In this case study, we explore how a peer-mentor discipline-specific program, called the Teaching Assistant Consultant (TAC) program at the University of Victoria, in Victoria, British Columbia, Canada, intersects with Matthews's five propositions for genuine Students as Partners (SaP) practice (2017). The propositions are: fostering inclusive partnerships, nurturing power-sharing relationships through dialogue and reflection, accepting partnership as a process with uncertain outcomes, engaging in ethical partnerships, and enacting partnership for transformation. Matthews (2017) proposed the propositions as a heuristic to initiate dialogue when designing students-as-partners programs. Despite the TAC program being designed prior to her heuristic, this case study investigates how the TAC program in a biology department maps onto her propositions and, subsequently, what changes need to be implemented to better represent the five propositions. Each of these propositions will be described below in relation to the TAC program in biology. 


\section{TAC PROGRAM}

Established in 2009, the TAC program positions experienced teaching assistants (TAs/graduate students) in academic departments to provide mentorship and guidance for all new TAs. TACs assist TAs in their teaching development through discipline-specific programming, teaching observations, one-on-one consultations, and referrals to appropriate campus resources. The goal is to enhance the educational experience of students, TAs, and those in the department. The TAC program pilot began with 17 departments and is now in every department with TAs - a total of 28 departments with one TAC per department. This means that all 700 TAs (approximately) each term have a peer mentor to help them with their teaching duties. The establishment of the TAC program provided the opportunity to develop a new role on campus that traversed boundaries by being a cross-disciplinary initiative (MercerMapstone et al., 2017) that fostered new perspectives about learning and teaching in higher education.

The underlying model used when designing the program was a community of practice (CoP) approach, which is about bringing together a community of people who share a similar interest (Wenger, 1998). This model was chosen because research has shown that graduate students who are well integrated into their departments are more successful and continue in higher education (Bellows, 2008). More importantly, a CoP model provides an understanding on how a shared approach to problem-solving mimics scholarly practice through inquiry, collaboration, and dissemination. To model CoP, the TAC program (managed by Cynthia) begins with instruction (one-week intensive) about mentoring, designing a department program, and conducting teaching observations. Additionally, TACs receive ongoing support from the program manager in the form of email or face-to-face communication; feedback on program learning outcomes, evaluation and instructional strategies; and consultation about issues that surface for TACs. Finally, TACs meet monthly as a group to share ideas, discuss issues and support each other. TACs are encouraged to mimic this model at the department level. Feedback from TAs who were part of the 2009-10 research pilot project consistently commended the TAC program for bringing TAs together to discuss and share their experiences and ideas, and for being a forum in which TAs can critically engage in an effort to support students' learning. With this approach, TACs are able to enhance colleagues' graduate student experience by providing support and a community-all features of a CoP. Through these mechanisms, the program exemplifies a process of equality from conceptualization to evaluation, which are important features of partnerships (Cook-Sather, Bovill, \& Felten, 2014).

Peer mentoring is sometimes referred to as informal mentoring (Cunningham \& Hillier, 2013). Peers greatly influence a TA's development as an instructor, but the information provided by peers may not be the best and could compound problems (Gardner \& Jones, 2011; Nyquist \& Sprague, 1998). To address this problem, the TAC program made the common informal experience of most TAs into a formal program with an informed and reliable mentor (Jungels, Brown, Stombler, \& Yasumoto, 2014). Besides being informed, peers make excellent mentors for individuals new to a role due to having much in common (Cosnefroy \& Buhot, 2013; Cunningham \& Hillier, 2013). TACs are experienced TAs within the same department that are familiar with the department culture, requirements, and duties associated with the TA role 
(for an example, see Bubbar, Dimopoulos, Korpan, \& Wild, 2017). Due to these factors, TAs can easily relate to TACs because TACs have recently been a new TA.

Our case study focuses on the University of Victoria's biology department's TAC program, which has one TAC (Gerry) for approximately 40 TAs each year. Despite literature acknowledging the importance of guiding biology TAs with inquiry-based teaching, developing their teacher identities towards a more learning-centred approach (Gormally, 2016), and the effectiveness of teaching observations with guided reflective discourse (Miller, Brickman, \& Oliver, 2014), biology did not join the TAC program until the fall of 2015.

Upon reading Matthews's propositions, the heuristic resonated with us and sparked an interest in seeing how the TAC program in biology exemplified the principles underlying students as genuine partners and exploring what changes could be made to better adhere to the principles. Therefore, to examine the TAC program in biology in relation to the propositions, we now describe SaP and Matthews's propositions. We explain challenges and issues encountered, as well as successes and incidents that proved to enrich the continuing development of the program.

\section{PROPOSITIONS FOR STUDENTS AS GENUINE PARTNERS}

SaP has been defined as "a metaphor for university education that challenges traditional assumptions about the identities of, and relationships between, learners and teachers" (Matthews, 2017, p. 1). This means that there is a respectful and meaningful learning relationship between staff or faculty and students working together on improving aspects of learning and teaching in higher education. This definition positions SaP as being about equitable collaboration and balanced reciprocity (Cook-Sather, Bovill, \& Felten, 2014) between all members involved (Matthews, 2016, emphasis in original). Matthews (2017) suggests that the following propositions provide a guiding heuristic that is not prescriptive but meant to initiate dialogue to expand SaP in higher education.

\section{Fostering inclusive partnerships}

The first proposition asks us to consider who engages in SaP and how that partnership is rendered. These questions are to ensure that partnership relationships do not consist only of select groups. Matthews (2017) states that the aim is to design students-as-partners programs that include students from all backgrounds engaged in a shared learning partnership because through fostering inclusion, students feel valued and acknowledged for who they are.

The opportunity for a student to initiate a program in a department is a rare occurrence. However, graduate students notice when there is discrepancy in support, and in more than one instance, have advocated for a TAC program in their department. This was the case when I (Gerry) approached the Senior Lab Instructors (SLIs) in biology. I had heard about the program, attended TAC-led workshops in the chemistry department, and strongly believed that biology TAs needed this support to help them feel valued and respected as teaching members in the department. The lack of mentorship for TAs is still a significant issue and dependent on many departmental factors (Aydin \& Hanuscin, 2013; Smollin \& Arluke, 2014; Vahey, Witkowsky, 
Rehling, \& Saifah, 2010), but more significant is that most do not receive any pedagogical support when they take on the TA role (Green, 2010; Nyquist \& Sprague, 1998).

The lack of pedagogical support was clearly understood by the SLIs, who are in charge of the lab portions of courses and are the teaching supervisors of TAs. Concerned about TA support and enhancing professional development but lacking time and resources, SLIs welcomed my suggestion of a TAC program in biology. From the beginning, I partnered with the chair, SLIs, and TAs to foster an inclusive teaching culture within the department.

\section{Nurturing power-sharing relationships through dialogue and reflection}

In the second proposition, Matthews states how SaP partnerships aim to be equitable so that partners can share their perspectives and experiences confidently to nurture power sharing. The TAC program aims to be equitable by acknowledging the expertise that TACs bring to their role, entering into a partnership with each TAC to support them in their development and rendering of the discipline-specific program. The framework that the program manager provides is about fostering the skills that TACs can use in their role. During the one-week intensive instruction, TACs engage in role-plays, scenarios, and modelling that encourage dialogue and reflective practice (Little \& Palmer, 2012). These foundational experiences give TACs the tools to nurture power-sharing relationships through dialogue and reflection with TAs, staff, and faculty in their department.

I fostered the same power-sharing relationships through dialogue and reflection in the biology department. In particular, realizing the effectiveness of guided self-reflection, I incorporated mandatory teaching observations, which has resulted in an attitudinal shift, with TAs becoming more reflective of their teaching practice and striving to improve to benefit student learning. Additionally, through a discipline-specific workshop, which ties together literature and biology-specific applications or examples, TAs are introduced to the concept of the Scholarship of Teaching and Learning (SoTL). One particular topic addressed in this workshop is classroom assessment techniques (CATs) (Angelo \& Cross, 1993). CATs are quick end-of-class post-assessments that inform the instructor if learning outcomes for the lesson were met but, more importantly, help build community and foster a more nurturing partnership between students and TAs. This was confirmed through a TAC-initiated survey administered to TAs, who commented that their students appreciated the CAT-the "muddiest point" - because it demonstrated that their TA took time to address their concerns and clear up issues. This example illustrates Healey, Flint, and Harrington's (2014) argument that learning, teaching, and assessment are areas where students and staff can engage as partners and where all voices can be considered equally.

\section{Accepting partnership as a process with uncertain outcomes}

A continual process of dialogue that acknowledges potential emotions involved in strengthening the "power-sharing learning relationship" (Matthews, 2017, p. 5) is the third proposition. Monthly TAC meetings provide a forum for continual dialogue about the TAC role. These meetings provide a safe place to share failures, problems, and charged encounters that occur for TACs with TAs, staff, and faculty. TACs recognize that not all individuals with whom 
they are interacting at the departmental level adhere to the principles underlying the TAC program, which has resulted in many emotional encounters. In these instances, TACs consult with the TAC program manager. Furthermore, TACs navigate difficulties that TAs encounter with students and course supervisors, which can result in negative outcomes, such as lack of confidence, motivation, and learning (for a full list of possible negative outcomes, see MercerMapstone et al., 2017, p. 13). The TAC intensive instruction week aims to prepare TACs for these types of encounters.

As learning is a partnership, the knowledge that TAs acquire from the TAC helps foster a stronger partnership, which opens up dialogue between the TAs and the TAC, allowing the TAC to guide TAs towards a more learning-centred approach in their classrooms. This has been accomplished through workshops that I present and in post-teaching observation meetings. TAs receive instruction on how to encourage students to take more control over their own learning and education, and to allow students the chance to explore. Just as it is important for TAs to remove the hierarchy between themselves and students, it is also important to maintain a nurturing partnership between TAs and the TAC; devoid of hierarchy, the result is a more power-sharing approach to learning and instruction. The biology TAC program helps create a safe space for TAs to express concerns and try out new teaching strategies, and it promotes the ability of TAs to challenge the TAC.

A positive unexpected outcome in the biology TAC program is the influx of veteran TAs (TAs who have been teaching for at least one year) asking me for continued support via teaching observations. Teaching and learning is a process, and the TAC program helps to foster a collective approach to both. Teaching can be emotional and the TAC program in biology has opened up the dialogue between TAs and the TAC about teaching and learning, thus promoting the power-sharing relationship.

\section{Engaging in ethical partnerships}

The fourth proposition highlights how ethical guidelines (such as values and conduct) should govern partnerships. Matthews (2017) states that ethical SaP practices have three components. First, reciprocity dictates that power sharing is between all involved, implying that all contribute their expertise in making decisions and setting goals for a SaP project. Matthews states how this is essential to ensure that students are not pressured to succumb to institutional needs. Second, "mutualistic partnerships" (Matthews, 2017, p. 5) need to be beneficial to all involved but need to be about positive work with no intention to harm anyone or any situation. Third, SaP is about the broader impact of the work and not just for the individuals involved (Matthews, 2017).

The structure of the TAC program encourages TACs to collaborate and contribute their expertise to the program to promote positive support within the department for all involved. This occurs through department-specific workshops and through guidance from the TAC program manager. However, there is freedom to create a program that is particularly relevant to each TAC's respective department. For example, in biology, I establish the program learning outcomes and evaluation methods that are specific to departmental needs and facilitate a 
workshop that not only introduces TAs to lesson planning but also provides prompts and guides using biology-specific examples.

During the intensive instruction week, TACs are introduced to the ground rules governing a safe space, respecting other people's opinions, and learning how to respectfully disagree. These same principles are incorporated in the very first workshop I put on for biology TAs, which introduces respectful and ethical partnerships between the TAC and the TA, but also between TAs and their students.

\section{Enacting partnership for transformation}

The last proposition is about the transformative power associated with individual agency. "Practitioners of SaP are first and foremost transforming their own realities by engaging in an alternative form of education within the traditional structures of universities" (Matthews, 2017, p. 6).

The TAC program is transformative for TACs. By taking on this role in the department and interacting with an institutionally sanctioned program, TACs hold a position within the university that bridges central programs with departmental needs. The professional development experienced by TACs is intensive, expansive, and positively affects their commitment to enhancing teaching and learning in higher education by recognizing their agency to enact change. Through this broader understanding, TACs are well positioned to challenge existing structures in the future.

Overall, the TAC program has been instrumental in initiating change not only for the biology department and its members, but also for me. The skills I have learned through the TAC program instruction and execution are applicable to many of my other roles. I have established strong time management skills and enhanced my peer support and mentorship skills while also becoming more self-reflective. My creative skills have been enhanced due to the abundance of different workshops I have offered throughout the years, and the uniqueness I try to maintain year to year even though some key workshops are repeated annually. I have also felt the impact of the TAC program through the communication and connections I now foster among many of the TAs, staff, and faculty members within the department.

\section{DISCUSSION AND CONCLUSION}

We began with investigating if the TAC program in biology models the propositions put forward by Matthews (2017) and exemplifies the principles underlying students as genuine partners. As described above, the TAC program in biology does exemplify Matthews's (2017) five propositions. However, the program could be strengthened to adhere better to them.

I specifically designed the TAC program in biology with strong ethics in mind, but the program as a whole could benefit from a greater focus on TAs practising and engaging, and less on overall theory. By this, I mean that rather than having workshops focused on understanding the theory behind CATs, perhaps I could provide a handout that outlines the significance of CATs, followed by a brief discussion, and then use the remaining workshop time to allow the TAs to practise different CATs and converse with their peers and the TAC as they are going through the process. It is sometimes mentioned by TAs that something reads well on paper or 
in a PowerPoint, but the actual application is difficult in a biology lab. Focusing the TAs more on specific information that is crucial to understand for implementation, coupled with time to practise and facilitate the use of CATs (or other teaching tactics), would greatly benefit the TAs. In doing so, the TAC program in biology would be strengthening the ethical partnership between the TAs and the TAC.

In general, the TAC program in biology does adhere to Matthews's (2017) five propositions for $\mathrm{SaP}$, and enacting partnership for transformation is a strength of the biology TAC program. Not only have I noticed the transformative effects of having a TAC program in biology, but the TAs themselves are commenting to each other, to the SLIs, and even to their students about pedagogical approaches they have learned or different teaching tactics they are interested in trying. The cultural shift in the biology department has been very strong, and every year there are more advocates for teaching and learning support, and for doing better for our students.

Mercer-Mapstone et al.'s (2017) article lists negative and positive outcomes for students that can result from partnership. There is evidence that the TAC program achieves most of the positive outcomes. For example, through program evaluation, TAs in the biology department have increased student engagement, motivation, and ownership for learning, positively shifted power dynamics between TAs and students, TAs and SLIs, and have an overall increase in their meta-cognitive learning. Additionally, the TAC program, built on principles of collaboration and community of practice (Korpan, 2010), has always aimed to foster graduate students' capacity to act (agency) and professional development, and acknowledges the significant contributions they make to the university teaching environment. SaP provides a framework to take the program further in developing students as genuine partners. Finally, cowriting this article exemplified balanced reciprocity through an equal exchange of ideas as we shared insights, collaboratively wrote, and reflected on the propositions together.

\section{NOTES ON CONTRIBUTORS}

Gerry Gourlay is a PhD candidate in the biology department at the University of Victoria. She is a recent LATHE (Learning and Teaching in Higher Education) certificate graduate from UVic and has been the TA Consultant (TAC) in the department for three years.

Cynthia Korpan is the Professional Development Program Manager at the Division of Learning and Teaching Support and Innovation at the University of Victoria. In this role, Cynthia develops programming and courses for faculty, sessional, and graduate students on campus.

\section{REFERENCES}

Angelo, T. A., \& Cross, K. P. (1993). Classroom assessment techniques: A handbook for college teachers. San Francisco, CA: Jossey-Bass. 
Aydin, S., \& Hanuscin, D. L. (2013). Learning to teach: Graduate assistants' expedition into teaching teachers. Journal of Higher Education, 3(3), 129-141.

Bellows, L. (2008). Graduate student professional development: Defining the field. Studies in Graduate \& Professional Student Development, 11, 2-19.

Bubbar, K., Dimopoulos, A., Korpan, C., \& Wild, P. (2017, June 4-7). An overview of the teaching assistant consultant program for developing competency in novice engineering graduate teaching assistants. Proceedings from the Canadian Engineering Education Association (CEEA) Conference, University of Toronto.

Cook-Sather, A., Bovill, C., \& Felten, P. (2014). Engaging students as partners in learning and teaching: A guide for faculty. San Francisco, CA: Jossey-Bass.

Cosnefroy, L., \& Buhot, E. (2013). Workplace learning impact: An analysis of French-secondary trainee teachers' perception of their professional development. Teachers and Teaching: theory and practice, 19(6), 679-694.

Cunningham, J., \& Hillier, E. (2013). Informal learning in the workplace: Key activities and processes. Education + Training, 55(1), 37-51.

Gardner, G. E., \& Jones, M. G. (2011). Pedagogical preparation of the science graduate teaching assistant: Challenges and implications. Science Educator, 20(2), 31-41.

Gormally, C. (2016). Developing a teacher identity: TAs' perspectives about learning to teach inquiry-based biology labs. International Journal of Teaching and Learning in Higher Education, 28(2), 176-192.

Green, J. L. (2010). Teaching highs and lows: Exploring university teaching assistants' experiences. Statistics Education Research Journal, 9(2), 108-122.

Healey, M., Flint, A., \& Harrington, K. (2014). Engagement through partnership: Students as partners in learning and teaching in higher education. York: Higher Education Academy. Retrieved from https://www.heacademy.ac.uk/blog/journeys-student-engagement-andpartnership

Korpan, C. (2010). Conversations and collaborations. Collected Essays in Learning \& Teaching, 4, 5 pages, Society for Teaching and Learning in Higher Education.

Little, D., \& Palmer, M. (2012). Training instructional consultants to use a coaching framework. In K. Brinko (Ed.), Practically speaking: A sourcebook for instruction consultants in higher education (pp. 208-216). Stillwater, OK: New Forums Press.

Matthews, K. E. (2016). Students as partners as the future of student engagement. Student Engagement in Higher Education Journal, 9(1), 1-5.

Matthews, K. E. (2017). Five propositions for genuine students as partners practice. International Journal for Students as Partners, 1(2), 1-9.

Mercer-Mapstone, L., Dvorakova, L. S., Matthews, K. E., Abbot, S., Cheng, B., Felten, P., Knorr, K., Marquis, E., Shammas, R., \& Swaim, K. (2017). A systematic literature review of students as partners in higher education. International Journal for Students as Partners, 1(1), 1-23.

Miller, K., Brickman, P., \& Oliver, J. S. (2014). Enhancing teaching assistants' (TAs') inquiry teaching by means of teaching observations and reflective discourse. School Science and Mathematics, 114(4), 178-190. 
Nyquist, J. D., \& Sprague, J. (1998). Thinking developmentally about TAs. In M. Marincovich, J. Prostko, \& F. Stout (Eds.), The professional development of graduate teaching assistants (pp. 61-88) Bolton, MA: Anker.

Smollin, L. M., \& Arluke, A. (2014). Rites of pedagogical passage: How graduate student instructors negotiate the challenges of first-time teaching. Teaching Sociology, 42(1), 2839.

Vahey, K., Witkowsky, P., Rehling, J., \& Saifah, S. (2010). Doctoral students make meaning of their experience: A constructivist inquiry. Studies in Graduate and Professional Student Development, 13, 2-22.

Wenger, E. (1998). Communities of practice: Learning, meaning, and identity. Cambridge: Cambridge University Press. 